\title{
Neonatal hypoglycaemia and withdrawal symptoms after exposure in utero to valproate
}

Finn Ebbesen, Annemette Joergensen, Eva Hoseth, Per-Henrik Kaad, Margrethe Moeller, Vibeke Holsteen, Mariane Rix

\begin{abstract}
Aims-To define, in a prospective study, the risk of hypoglycaemia-defined as blood glucose concentration $<1.8 \mathrm{mmol} /$ 1 -in term infants exposed in utero to valproate and to describe the withdrawal symptoms.

Methods-Twenty epileptic women were treated with valproate only during pregnancy and two were treated with valproate and carbamazepine. In the first trimester, the daily median dose of valproate was 1.0 $g$ (range $0.3-4.2)$ and in the third trimester 1.2 g (range 0.3-4.8).

Results-Thirteen of the 22 infants became hypoglycaemic. One infant had eight episodes of hypoglycaemia, one had three episodes, two had two episodes, and nine had one episode each. The lowest blood glucose concentration was 1.0 mmol/1. All episodes were asymptomatic. The maternal mean plasma concentration of total valproate during the third trimester correlated negatively with blood glucose concentration one hour after delivery $(p<0.0003)$ and with the development of hypoglycaemia $(p<0.0001)$. There was no evidence for hyperinsulinaemia as the cause of hypoglycaemia. Ten infants developed withdrawal symptoms, which correlated positively with the mean dose of valproate in the third trimester and the concentration of the free fraction of valproate in maternal plasma at delivery ( $\mathrm{p}<0.02)$.
\end{abstract}

Conclusions-Infants exposed to valproate in utero had a significantly elevated risk of hypoglycaemia, and withdrawal symptoms were often observed.

(Arch Dis Child Fetal Neonatal Ed 2000;83:F124-F129)

Neonatology, Aalborg

Hospital, Denmark

F Ebbesen

$\mathrm{V}$ Holsteen

M Rix

Department of

Gynecology and

Obstetrics

A Joergensen

E Hoseth

M Moeller

Department of Paediatrics, Hjoerring

Hospital, Denmark

P-H Kaad

Correspondence to:

Dr Ebbesen, Department of Paediatrics, Aalborg

Hospital, P O Box 561, 9100

Aalborg, Denmark

email: ul9091@aas.nja.dk

Accepted 27 March 2000 proate in plasma, and the prescribed dose of valproate has been reduced considerably.

In this study, we have analysed prospectively and consecutively the incidence of hypoglycaemia in neonates exposed to valproate in utero and recorded withdrawal symptoms as well as minor abnormalities and major malformations.

\section{Materials and methods}

During the period July 1993 to February 1997 in the county of North Jutland, Denmark, we consecutively studied all infants born to epileptic mothers treated during pregnancy with valproate alone or in combination with other antiepileptic drugs. Preterm infants (gestational age $<37$ weeks) and second twins were excluded, but major malformations and minor abnormalities were recorded.

During the study period, 24500 infants were born in the county. Twenty two infants and their mothers were included. Nineteen mothers had primary generalised epilepsy and three had complex partial epilepsy (table 1). Twenty mothers received valproate alone and two both valproate and carbamazepine (table 1). The pregnant epileptic women were followed according to international standards. They were seen once a month by a neurologist, and total and free drug plasma concentrations were measured and their future antiepileptic dose prescribed. The dose was adjusted according to the prepregnancy plasma level to maintain a constant concentration of the free fraction of valproate to ensure, as far as possible, absence of seizures. The plasma concentrations were measured as fasting values at $8-10 \mathrm{am}$. The concentrations of valproate and carbamazepine were measured by immunofluorescence. ${ }^{5}$

All women were offered an obstetrical ultrasound investigation and an amniocentesis. Amniocentesis was performed in 11 cases and an ultrasound investigation in all cases. In one case a chorionic villous biopsy was performed. The concentrations of $\alpha$ fetoprotein in the amniotic fluid and the fetal chromosome analyses were normal. No therapeutic abortions were performed. During pregnancy the women abstained from, or consumed only small amounts of, alcohol.

In three cases, pregnancy was complicated by mild hypertension or mild pre-eclampsia, which was treated with labetalol. This drug does not affect the level of blood glucose in neonates. ${ }^{6}$ None of the women were treated with $\beta$-sympathomimetics, ${ }^{7}$ and none received glucose infusions during labour.

The infants were observed in the neonatal unit from the first hour of life, and every eight 


\begin{tabular}{|c|c|c|c|c|c|c|c|}
\hline \multirow{2}{*}{$\begin{array}{l}\text { Mother } \\
\text { no }\end{array}$} & \multirow[b]{2}{*}{ Type of epilepsy } & \multirow{2}{*}{$\begin{array}{l}\text { Epileptic attack } \\
\text { during pregnancy }\end{array}$} & \multirow[b]{2}{*}{ Medication } & \multicolumn{3}{|c|}{$\begin{array}{l}\text { Daily dose of antiepileptic drug(s) in } g / 24 \text { hours }+ \text { range of plasma concentrations of } \\
\text { (total valproate) and [free valproate] in } \mu \text { molll }\end{array}$} & \multirow{2}{*}{$\begin{array}{l}\text { Poor } \\
\text { compliance }\end{array}$} \\
\hline & & & & 1st trimester & $2 n d$ trimester & 3rd trimester & \\
\hline 1 & Primary generalised & & Valproate & 1.0 & $1.0 \rightarrow 1.5(238-348)[29-63]$ & $1.5(226-338)[28-54]$ & \\
\hline 2 & Primary generalised & & Valproate & $0.9(310-343)$ & 0.9 & $0.9 \rightarrow 2.1(212-362)$ & \\
\hline 3 & Primary generalised & & Valproate & 0.6 & $0.6(243)$ & $0.6 \rightarrow 2.1(250-583)$ & \\
\hline 4 & Primary generalised & & Valproate & 0.6 & $0.6 \rightarrow 0.9(247)$ & $0.9(298-427)$ & \\
\hline 5 & Primary generalised & & Valproate & $1.0(412)[27]$ & $1.0(306-381)[26-39]$ & $1.0(262-304)[29-35]$ & \\
\hline 6 & Complex partial & + & Valproate & 1.1 & 1.1 & $1.1 \rightarrow 1.5(280-319)$ & \\
\hline 7 & Primary generalised & & Valproate & 1.0 & $1.0(275-422)[38-63]$ & $1.3(274-408)[42-55]$ & \\
\hline 8 & Primary generalised & & Valproate & $1.0(122)[7]$ & $1.0(266-267)[27]$ & $1.0(146-204)[17-26]$ & \\
\hline 9 & Primary generalised & & Valproate & $0.5(329)[32]$ & $0.5(239-275)[21-25]$ & $0.5(222-247)[23-24]$ & \\
\hline 10 & Primary generalised & & Valproate & $1.0(273-290)[24-28]$ & $1.0(264-290)[23-38]$ & $1.0(174-392)[21-53]$ & \\
\hline 11 & Primary generalised & & Valproate & $1.0(607)[50]$ & $1.0(390-536)[49-56]$ & $1.0(251-304)[31-56]$ & \\
\hline 12 & Primary generalised & & Valproate & $0.9(327)$ & $0.9(238-309)$ & $1.2 \rightarrow 1.5(334-362)$ & \\
\hline 13 & Primary generalised & & Valproate & $0.8(269)[18]$ & $0.8 \rightarrow 1.0(281-321)[19-25]$ & $1.0(272-360)[35-42]$ & \\
\hline 14 & Primary generalised & & Valproate & $1.6(434)[43]$ & $1.6(373-615)[65-70]$ & $1.6(308-422)[30-52]$ & \\
\hline 15 & Primary generalised & & Valproate & $1.5(283)[20]$ & $1.5(249-314)[24-38]$ & $1.5(269-312)[29-33]$ & \\
\hline 16 & Primary generalised & & Valproate & $1.2(416)[55]$ & $1.2 \rightarrow 1.5(287-310)[20-47]$ & $1.5(278-314)[30-51]$ & \\
\hline 17 & Primary generalised & & Valproate & $1.0(302)[20]$ & $1.0(223-260)[20-27]$ & $1.0(179-225)[19-33]$ & \\
\hline 18 & Primary generalised & & Valproate & $0.3(78)[3]$ & $0.3(77-82)[5]$ & $0.3(52-63)[5]$ & \\
\hline 19 & Primary generalised & & Valproate & $0.9(264-373)[22-40]$ & $0.9(236-334)[34-58]$ & $0.9(195-260)[31-45]$ & \\
\hline 20 & Primary generalised & & Valproate & $1.0(568-609)[62]$ & $1.0(469-537)[56-64]$ & $1.0(422-436)[51-69]$ & \\
\hline \multirow[t]{2}{*}{21} & Complex partial & + & Valproate & 4.2 & $4.8(22-446)[6-81]$ & $4.8(238-316)[44-78]$ & \multirow[t]{4}{*}{+} \\
\hline & & & carbamazepine & 2.4 & $2.8(6-44)[2-10]$ & $2.8(23-29)[7-16]$ & \\
\hline \multirow[t]{2}{*}{22} & Complex partial & + & Valproate & 1.5 (289) [26] & $1.5(108-165)[15-26]$ & $1.5(123-141)[12]$ & \\
\hline & & & carbamazepine & $1.0(26)[7]$ & $1.0(25)[5]$ & $1.0(22-29)[5-11]$ & \\
\hline
\end{tabular}

hours withdrawal symptoms such as irritability, jitteriness, hypertonia, seizures, and vomiting were recorded.

Glucose levels in the umbilical cord blood (mixed arteriovenous blood) as well as in capillary blood were measured at 1, 2, 4, 6, 12, 18 and 24 hours of age and then every eight hours until the 5 th day of age. The samples at 1,2 and 4 hours post partum were collected independently of feeding time. After this, samples were collected just before feeding.

Capillary blood samples were collected by heel prick on prewarmed feet into $20 \mu \mathrm{l}$ heparinised micropipettes containing fluoride, and immediately analysed. Glucose concentration was measured using the glucose dehydrogenase photometric method on an Hitachi 911 analyser. ${ }^{8}$ The day to day combined preanalytical and analytical standard deviation was 0.15 $\mathrm{mmol} / \mathrm{l}$.
Hypoglycaemia was defined as a glucose concentration below $1.8 \mathrm{mmol} / 1$ (= $32.4 \mathrm{mg} /$ dl) as in our previous study, ${ }^{4}$ as we have not yet found sufficient evidence to change this definition. ${ }^{39} 10$

Concentrations of proinsulin, ${ }^{11}$ insulin, ${ }^{12}$ and C peptide ${ }^{13}$ in umbilical cord plasma were determined by enzyme immunoassay and radioimmunoassay.

The infants received an early feed-that is, within the first hour of life-and were thereafter breast fed about eight times a day. Breast feeding was supplemented with formula milk for an average of 2 days (range $0-6$ ). One infant was exclusively formula fed. The main reason for supplementation was feeding problems because of withdrawal symptoms (table 2).

The following liver function tests were carried out on all hypoglycaemic infants: plasma concentrations of aspartate aminotransferase,

Table 2 Infant data

\begin{tabular}{|c|c|c|c|c|c|c|c|c|c|c|c|}
\hline \multirow{2}{*}{$\begin{array}{l}\text { Infant } \\
\text { no }\end{array}$} & \multirow[b]{2}{*}{ Sex } & \multirow{2}{*}{$\begin{array}{l}\text { Gestational } \\
\text { age } \\
\text { (weeks) }\end{array}$} & \multirow{2}{*}{$\begin{array}{l}\text { Birth } \\
\text { weight }(g)\end{array}$} & \multirow{2}{*}{$\begin{array}{l}\text { Apgar } \\
\text { score } 1-5 \\
\text { minutes }\end{array}$} & \multicolumn{5}{|c|}{ Withdrawal symptoms } & \multirow{2}{*}{$\begin{array}{l}\text { Treatment of } \\
\text { symptoms }\end{array}$} & \multirow[b]{2}{*}{ Minor abnormalities } \\
\hline & & & & & Irritability & Fitteriness & Hypertonia & Seizures & Vomiting & & \\
\hline 1 & $\mathrm{f}$ & 42 & 2650 & $9-10$ & + & + & + & & + & & $\begin{array}{l}\text { Ptosis, rough curly hair, epicantic } \\
\text { folds, hypertelorism, deep groove } \\
\text { below the lower lids }\end{array}$ \\
\hline 2 & $\mathrm{~m}$ & 39 & 2950 & $10-10$ & + & + & + & & + & Phenobarbital & \\
\hline 3 & $\mathrm{~m}$ & 42 & 4000 & $10-10$ & & + & & & + & & \\
\hline 4 & $\mathrm{f}$ & 41 & 3580 & $10-10$ & & & & & & & \\
\hline 5 & $\mathrm{~m}$ & 41 & 3925 & $10-10$ & & & & & & & \\
\hline 6 & $\mathrm{f}$ & 40 & 3880 & $7-10$ & + & + & + & & & & \\
\hline 7 & $\mathrm{~m}$ & 39 & 3400 & $6-10$ & + & + & & & & & \\
\hline 8 & $\mathrm{f}$ & 41 & 3070 & $8-10$ & + & + & + & & + & & Small unusually shaped ears \\
\hline 9 & $\mathrm{~m}$ & 42 & 3715 & $10-10$ & & & & & & & \\
\hline 10 & $\mathrm{~m}$ & 41 & 3820 & $10-10$ & + & + & + & & & & \\
\hline 11 & $\mathrm{f}$ & 42 & 4110 & $10-10$ & & & & & & & \\
\hline 12 & $\mathrm{~m}$ & 38 & 3030 & $9-10$ & + & + & & & & & \\
\hline 13 & $\mathrm{~m}$ & 41 & 4595 & $10-10$ & & & & & & & \\
\hline 14 & $\mathrm{f}$ & 39 & 2680 & $5-6$ & + & + & + & + & + & $\begin{array}{l}\text { Phenobarbital } \\
\text { Diazepam }\end{array}$ & \\
\hline 15 & $\mathrm{~m}$ & 40 & 3960 & $10-10$ & & & & & & & $\begin{array}{l}\text { Complete syndactyly of the right } \\
4 \text { th- } 5 \text { th toe }\end{array}$ \\
\hline 16 & $\mathrm{~m}$ & 37 & 3000 & $9-10$ & & & & & & & \\
\hline 17 & $\mathrm{~m}$ & 38 & 4240 & $8-9$ & & & & & & & \\
\hline 18 & $\mathrm{f}$ & 40 & 3600 & $10-10$ & & & & & & & \\
\hline 19 & $\mathrm{f}$ & 38 & 3350 & $10-10$ & & & & & & & \\
\hline 20 & $\mathrm{~m}$ & 40 & 3755 & $10-10$ & & & & & & & \\
\hline 21 & $\mathrm{~m}$ & 39 & 3180 & $10-10$ & + & + & + & & & Phenobarbital & Small unusually shaped ears \\
\hline 22 & $\mathrm{~m}$ & 41 & 3420 & $9-10$ & & & & & & & \\
\hline
\end{tabular}


alkaline phosphatase, albumin, conjugated and unconjugated bilirubin, and coagulation factors II, VII and X were measured.

At delivery, maternal plasma concentrations and umbilical cord concentrations of the free and total fractions of valproate were measured. Neonatal plasma drug concentrations were measured on the second and fourth day of age.

Written informed consent was obtained from the parents. The protocol was approved by the local ethics committees.

The statistical methods used were the Mann-Whitney rank sum test for unpaired observations, Fisher's exact test, and stepwise forward logistic regression analysis. The significance level was set at $5 \%$.

According to the study design, three infants were excluded: two preterm infants and a second twin (first twin was infant no 16). One of the preterm infants had the following malformations: hypoplasia of the left femur, aplasia of the left fibula, and duplication of the distal part of the right thumb.

REFERENCE DATA

A reference group, consisting of 223 healthy term infants of appropriate size for gestational age, was studied during the first 96 hours after birth. ${ }^{14}$ Capillary blood glucose concentration was measured at one of the following times: 1 , $2,4,6,12,24,48,72,96$ hours post partum. Each infant had one measurement. In another 22 infants, glucose concentration in umbilical cord blood was measured. The blood samples were taken independently of feeding times. About 20 samples were taken at each time point from different infants. In addition, concentrations of proinsulin, insulin, and $\mathrm{C}$ peptide in umbilical cord plasma were determined. The infants were breast fed within the first hour of delivery and then every second or third hour. None of the infants had any neurological symptoms and none of the mothers had epilepsy.

The reference data were collected at the same hospital (Aalborg) and in the same period as the study material, and the blood glucose concentrations were determined at the same laboratory.

\section{Results}

Table 1 gives data on the mothers in the study. During the first trimester, the daily dose of valproate varied from 0.3 to $4.2 \mathrm{~g}$ (median $1.0 \mathrm{~g}$ ) and during the third trimester from 0.3 to 4.8 $\mathrm{g}$ (median $1.2 \mathrm{~g}$ ). In 10 women, the valproate dose had to be increased. During pregnancy, three women suffered from epileptic seizures and one of these women showed poor compliance.

Table 2 gives data on the infants in the study. Fourteen boys and eight girls were included. The median gestational age was 40 weeks (range 37-42) and the median birth weight 3590 g (range 2650-4595). Fifteen infants were delivered vaginally and seven by caesarean section. Two infants ( 1 and 14) were small for gestational age and the latter had asphyxia. On admission to the neonatal unit all infants had a temperature $>36.5^{\circ} \mathrm{C}$.

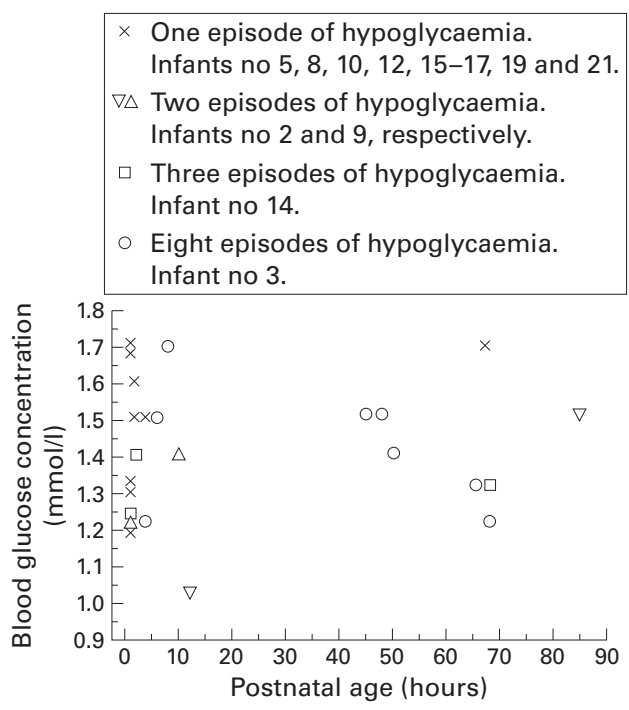

Figure 1 Scatter plot of postnatal age of hypoglycaemic episodes against blood concentration in infants exposed in utero to valproate.

In 13 of the 22 infants, blood glucose concentrations fell below $1.8 \mathrm{mmol} / 1$ (fig 1 ). In seven infants, the first episode of hypoglycaemia occurred within one hour of birth, in three within two hours, in one within four hours, in one within 12 hours, and in one within 67 hours (fig 1). Figure 2 shows the cumulated incidence of hypoglycaemia. All hypoglycaemic infants were treated with an intravenous bolus of glucose $200 \mathrm{mg} / \mathrm{kg}$ body weight, followed by a continuous infusion of glucose at a maximum rate of $2-8 \mathrm{mg} / \mathrm{kg} / \mathrm{min}$ (median 4 ). The median time of infusion was 31 hours (range 25-123). Infants 3 and 14 were also treated with hydrocortisone.

The number of episodes of hypoglycaemia varied: one infant had eight, one had three, two had two, and nine each had one episode (fig 1). The lowest concentration of blood glucose measured was $1.0 \mathrm{mmol} / 1$ (fig 1 ). The hypoglycaemic infants were all asymptomatic. When neurological symptoms existed and did not disappear despite glucose infusion, we concluded that they were not related to hypoglycaemia and were recorded as withdrawal symptoms.

Figure 3 shows median concentrations of blood glucose at different times after delivery.

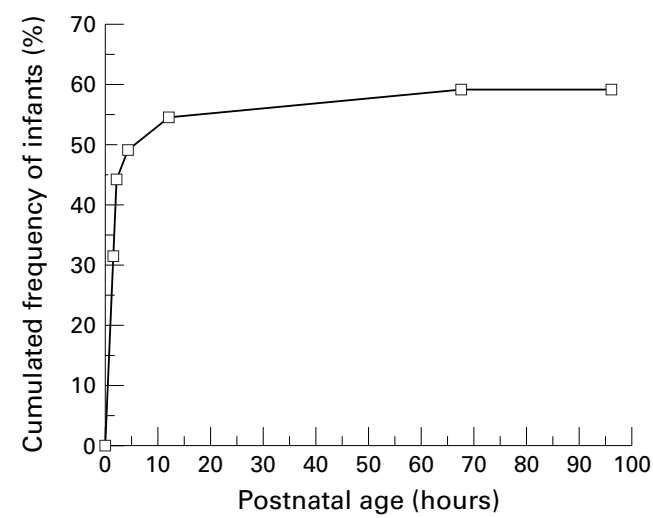

Figure 2 Cumulated frequency of infants exposed in utero to valproate who developed hypoglycaemia during the first 96 hours of age. 


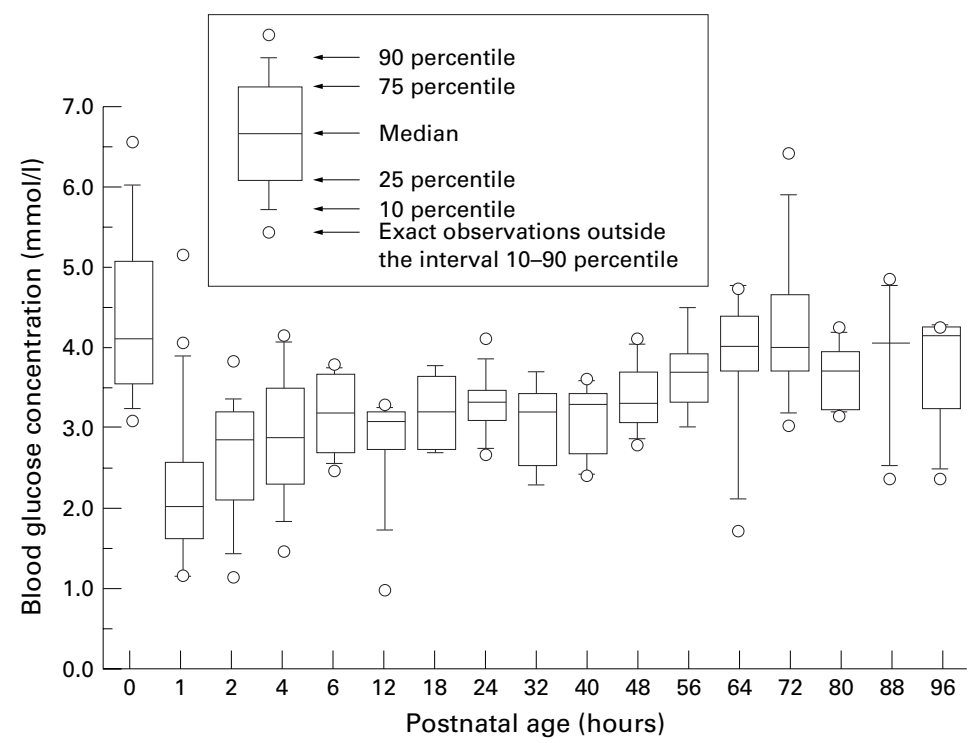

Figure 3 Blood glucose concentration in infants exposed in utero to valproate during the first 96 hours of life. (range 7-78), $27 \mathrm{pmol} / 1$ (range $<5-33$ ), and $340 \mathrm{pmol} / 1$ (range $<100-1041$ ) respectively.

In the reference group, the median concentration of glucose in umbilical cord blood and the plasma concentrations of proinsulin, insulin, and $\mathrm{C}$ peptide were $4.9 \mathrm{mmol} / 1$ (range $1.9-$ 7.4), $14 \mathrm{pmol} / 1$ (range 4.4-35), $24 \mathrm{pmol} / 1$ (range 8.6-97), and $314 \mathrm{pmol} / 1$ (range 116527). There was no significant difference between the two groups ( $p>0.05$; MannWhitney test).

In the third trimester and at delivery, the median maternal plasma concentrations of valproate $(\mu \mathrm{mol} / 1)$ were as follows: total fraction 285 (range 59-431) and 252 (range 14-399) and free fraction 32 (range 5-61) and 39 (range $<5-148$ ).

The median plasma concentrations of valproate $(\mu \mathrm{mol} / \mathrm{l})$ in the umbilical cord and neonate 26 and 73 hours after birth were as follows: total fraction 336 (range 24-589), 224 (range 18-449), and 123 (range 38-226) and free fraction 40 (range 5-87), 32 (range $<5-$ 97 ), and 13 (range 3-31) respectively.

Ten infants developed withdrawal symptoms such as irritability, jitteriness, hypertonia, seizures, and vomiting (table 2). Three infants needed to be fed by tube, and one had convulsions. Withdrawal symptoms began 12-24 hours after birth and lasted two to seven days. Three infants were treated with phenobarbital, and the convulsive infant was treated with diazepam as well. The development of withdrawal symptoms correlated positively with the mean dose of valproate in the third trimester and the concentration of the free fraction of valproate in maternal plasma at delivery ( $\mathrm{p}<0.02 ;$ Mann-Whitney test). There was a positive but statistically insignificant correlation between the mean plasma concentration of the free and total fraction of valproate in the third trimester, the maternal concentration of the total fraction of valproate at delivery, the concentrations of free and total fractions of valproate in the infant at delivery, and development of symptoms in the infant.

Liver function tests, except unconjugated bilirubin, gave normal results, except for one infant (no 14) with asphyxia, who had elevated plasma aspartate aminotransferase activity (162 U/1; normal value < $90 \mathrm{U} / 1$ ).

None of the infants had major malformations. Four infants had minor abnormalities (table 2). The facial features of infant 1 were characteristic of fetal valproate syndrome. ${ }^{15}$

\section{Discussion}

In this study, the median dose of valproate given to the pregnant epileptic women was significantly lower than in our previous study ${ }^{4}$ : median dose $1.0 \mathrm{~g}$ (range $0.3-4.2$ ) in the first trimester and $1.2 \mathrm{~g}$ (range $0.3-4.8$ ) in the third compared with $1.5 \mathrm{~g}$ (range 0.0-4.8) and $2.5 \mathrm{~g}$ (range 0.9-6.6) respectively. In this study, only one patient was treated with more than $2.1 \mathrm{~g}$ valproate daily. Some $90 \%$ of the women were treated with valproate alone compared with $65 \%$ in the previous study. ${ }^{4}$

In our previous study on 17 infants, hypoglycaemia was found in four. Blood 
glucose was measured in nine infants because of neurological symptoms, but the symptoms persisted in spite of glucose infusion. These findings suggested that exposure to valproate in utero may cause neonatal hypoglycaemia. However, blood glucose concentration was not measured systematically, and therefore the risk of hypoglycaemia could not be predicted.

In this study, we systematically determined blood glucose concentration in infants of epileptic women during the first 96 hours after birth. Some $59 \%$ (13 of 22) developed hypoglycaemia and in all cases it was asymptomatic and moderate, the lowest blood glucose concentration measured being $1.0 \mathrm{mmol} / \mathrm{l}$. Hypoglycaemia was more common during the first few hours after birth, but was seen as late as 88 hours post partum. Hypoglycaemia in these infants of epileptic mothers seems to be more common than in mature infants of diabetic mothers, ${ }^{16}{ }^{17}$ in which the cause is known to be hyperinsulinaemia. ${ }^{18}$

Repeated episodes of hypoglycaemia were seen in four of the infants, with a maximum of eight episodes. Lucas et $a \beta^{\beta}$ found that the number of separate days in which hypoglycaemia (plasma glucose concentration $<2.6$ $\mathrm{mmol} / \mathrm{l}$ ) occurred in preterm infants was strongly related to a reduced mental and motor development score and to an increased incidence of cerebral palsy at 18 months of age. During episodes of hypoglycaemia, ketone bodies generated from fatty acids may be an alternative substrate for cerebral metabolism, but valproate inhibits this ketogenesis. ${ }^{19} 20$ Thus hypoglycaemia in infants exposed to valproate in utero may be hypoketotic. Impaired psychomotor development is often seen in infants of epileptic mothers treated during pregnancy with valproate. ${ }^{415212223}$ One of the causes may be unrecognised hypoglycaemia.

In one of the infants in this study (no 14), there could have been an alternative cause of the hypoglycaemia, as the infant was both small for gestational age and asphyxiated.

In this study, neonatal hypoglycaemia was defined as a blood glucose concentration $<1.8$ $\mathrm{mmol} / \mathrm{l}$ as in our previous study. Other investigators define hypoglycaemia as a blood glucose concentration $<2.2 \mathrm{mmol} / 1$ or $<2.6 \mathrm{mmol} /{ }^{24}$ If we had defined hypoglycaemia in this way, the values would have been $77 \%$ (17 infants) and $91 \%$ (20 infants) respectively.

In the reference group, blood glucose concentration was determined after delivery in 223 infants. Only one of these had a low blood glucose concentration $(1.4 \mathrm{mmol} / \mathrm{l})$ at 1 hour of age. Compared with this, blood glucose concentration was significantly lower at 1 hour of age and the incidence of hypoglycaemia significantly higher in the valproate exposed group. Similar but statistically insignificant correlations were found two hours post partum.

Confirmation that valproate exposure in utero is the cause of hypoglycaemia would require a study in which infants not exposed to valproate in utero were included and the blood glucose concentrations measured at the same times as in the exposed infants. Such a study was impossible to carry out. We therefore compared the group of infants exposed to valproate and their incidence of hypoglycaemia with a group of healthy term infants of appropriate size for gestational age, although there may be alternative causes of hypoglycaemia in the infants exposed to valproate. This was seen in the infant who was both small for gestational age and asphyxiated.

In the valproate exposed group, the infants often received breast milk supplemented with formula milk, usually because of feeding problems caused by withdrawal symptoms, but in the reference group none of the infants received supplements. Supplements must have tended to prevent hypoglycaemia in the valproate exposed group, but in spite of this, the incidence of hypoglycaemia was found to be very high.

Preterm infants were excluded for the following reasons: they often receive infusions of glucose immediately after birth; they are often hypoglycaemic because of prematurity; they often have complicating diseases; the amount of blood required for measurement is relatively large compared with the infant's blood volume.

In the valproate exposed group, blood glucose concentration one hour after birth was found to correlate negatively with the mean plasma concentration of total valproate in the third trimester.

In conclusion, the exposure to valproate in utero (and consequently in the first days after birth) was the cause of hypoglycaemia, and the infants exposed to valproate had a significantly higher risk of developing hypoglycaemia, and the repeated episodes of hypoglycaemia occurred often. We recommend that blood glucose is repeatedly and routinely measured, especially in the first hours after birth, in infants exposed in utero to valproate.

To investigate if hypoglycaemia could be due to hyperinsulinism, we measured concentrations of proinsulin, insulin, and $\mathrm{C}$ peptide in umbilical cord blood. These concentrations and those of blood glucose were not significantly different from those measured in umbilical cord blood of the reference group of normal healthy term infants. Another argument against hyperinsulinism being the cause of hypoglycaemia is that the infants with hypoglycaemia were infused with glucose at a median rate of $4 \mathrm{mg} / \mathrm{kg} / \mathrm{min}$ (range $2-8)^{25}{ }^{26}$ and they had a normal birth weight ${ }^{27}$ and did not resemble infants of diabetic mothers. ${ }^{28}$ In conclusion, we found no evidence for hyperinsulinism ${ }^{29}$ as the cause of hypoglycaemia in infants exposed in utero to valproate.

Valproate can affect synthesis in the liver. ${ }^{19}{ }^{30-33}$ Thus an increased plasma concentration of ammonium ${ }^{19}{ }^{33}$ and a decreased concentration of $\beta$-hydroxybutyrate, ${ }^{19}$ albumin, fibrinogen, ${ }^{30}$ and carnitine ${ }^{1931}$ have been found in children treated with valproate for febrile convulsions or epilepsy. Similar depletion of neonatal fibrinogen caused by valproate has been described. ${ }^{32}$ Valproate given to infant mice led to reduced liver glycogen. ${ }^{34}$ Administration of valproate was found to inhibit 
mitochondrial $\beta$-oxidation of fatty acids in humans and rats, ${ }^{35}$ and patients with enzymatic $\beta$-oxidation defects often have neonatal hypoglycaemia ${ }^{36}{ }^{37}$ as the result of decreased gluconeogenesis. This is in accordance with the hypoketonaemia of children treated with valproate. ${ }^{19}{ }^{20}$ In isolated rat hepatocytes, valproate inhibits gluconeogenesis. ${ }^{38}$ Therefore decreased gluconeogenesis caused by valproate seems to be well documented, but because hypoglycaemia in infants exposed in utero to valproate is seen in this study as early as within the first few hours after birth, decreased gluconeogenesis is considered to be a contributory cause at the most. The most important cause of hypoglycaemia may therefore be reduced liver glycogen and/or impaired glycogenolysis.

Although the maternal dose of valproate was reduced and the frequency of monotherapy increased in this study, the incidence of major malformations and minor abnormalities was lower than in the previous study. ${ }^{4}$ In that study, five of 17 infants had major malformations and nine had minor abnormalities compared with one of the three excluded infants with major malformations and four of the 22 study infants with minor abnormalities in this one. The reduced incidence of major malformations and minor abnormalities seems to confirm the dependence on the dose of valproate, which is in accordance with our previous study and the study of Jäger-Roman $\mathrm{et} \mathrm{al.}{ }^{21}$

Ten infants had neurological symptoms such as irritability, jitteriness, hypertonia, seizures, and feeding problems. These symptoms correlated positively with the dose of valproate as in the previous study, ${ }^{4}$ as well as with the maternal concentration of the free fraction of valproate at delivery. The symptoms began $12-24$ hours after birth and were regarded as withdrawal symptoms, because they did not disappear after infusion of glucose. In one case, asphyxia may have been an alternative cause of the neurological symptoms. Thus withdrawal symptoms are often seen in infants exposed in utero to valproate in commonly recommended doses, as also reported by Koch et l. $^{22}$

1 Fluge G. Neurological findings at follow-up in neonatal hypoglycaemia. Acta Paediatr Scand 1975;64:629-34.

hypoglycaemia. Acta Paediatr Scand 1975;64:629-34.
2 Koivisto M, Blanco-Sequeiros M, Karuse U. Neonatal Koivisto M, Blanco-Sequeiros M, Karuse U. Neonatal
symptomatic and asymptomatic hypoglycaemia: follow-up study of 151 children. Dev Med Child Neurol 1972;14:603-14

3 Lucas A, Morley R, Cole T. Adverse neurodevelopmental outcome of moderate neonatal hypoglycaemia. BMF 1988;297:1304-8.

4 Thisted E, Ebbesen F. Malformations, withdrawal manifestations, and hypoglycaemia after exposure to valproate in utero. Arch Dis Child 1993;69:288-91.

5 Dandliker WB, Feigen GA. Quantification of the antigenantibody reaction by the polarization of fluorescence. Biochem Biophys Res Commun 1961;5:299-304.

6 Pickles C, Symonds E, Pipkin F. The fetal outcome in a randomized double-blind controlled trial of labetalol versus placebo in pregnancy-induced hypertension. Br f Obstet placebo in pregnancy-ind

7 Epstein M, Micholls E, Stubblefield P. Neonatal hypoglycemia after beta-sympathometic tocolytic therapy. $\mathscr{f}$ Pediatr 1979;94:449-53.

8 Rindfrey $\mathrm{H}$, Helger R, Lang $\mathrm{H}$. Kinetic determination of glucose concentration with glucose dehydrogenase. Four nal of Clinical Chemistry and Biochemistry 1977;15:217-20.

9 Pryds O, Christensen NJ, Friis-Hansen B. Increased cerebral blood flow and plasma epinephrine in hypoglycemic, preterm neonates. Pediatrics 1990;85:172-6.
10 Koh THHG, Aynsley-Green A, Tarbit M, Eyre JA. Neural dysfunction during hypoglycaemia. Arch Dis Child dysfunction dur $1988 ; 63: 1353-8$.

11 Kjems L, Roeder M, Dinesen B, et al. Highly sensitive enzyme immunoassay for proinsulin immunoreactivity with use for two monoclonal antibodies. Clin Chem 1993;39:2146-50.

12 Andersen A, Dinesen B, Joergensen P, Poulsen F, Roeder M. Enzyme immunoassay for intact human insulin in serum or plasma. Clin Chem 1993;39:578-82.

13 Heding L. Radioimmunological determination of human c-peptide in serum. Diabetologica 1975;11:541-8

14 Hoseth E, Joergensen A, Ebbesen F, Moeller M. Blood glucose levels in a population of healthy, breast-fed, term infants of appropriate size for gestational age. Arch Dis Child Fetal Neonatal Ed 2000:82:

15 Ardinger HH, Atkin JF, Blackston RD, et al. Vertification of the fetal valproate syndrome phenotype. Am f Med Genet 1988;29:171-85.

16 Stiete H, Stiete S, Jährig D, Briese V, Willich S. Risikogruppen neugeborener diabetischer Mütter in Abhängigkeit von Ihrem somatischen Outcome und der mütterlichen diabetischen Stofwechsellage in der Schwangerschaft. $Z$ Geburtshilfe Neonatol 1995;199:156-62.

17 Bracero L, Cassidy S, Byrne D. Effect of gender on perinatal outcome in pregnancies, complicated by diabetes. Gynecol Obstet Invest 1996;41:10-14.

18 Heding L, Persson B, Stangenberg M. B-cell function in newborn infants of diabetic mothers. Diabetologica 1980;19:427-32.

19 Toksoy H, Tanzer F, Atalay A. Serum carnitine, betahydroxybutyrate and ammonia levels during valproic acid therapy. Turk f Pediatr 1995;37:25-9.

20 Thurston J, Carrol J, Dudson W, Haukart R, Tasch V. Chronic valproate administration reduces fasting ketonemia in children. Neurology 1983;33:1348-50.

21 Jäger-Roman E, Deich A, Jakob S, et al. Fetal growth, major malformations, and minor abnormalities in infants born to women receiving valproic acid. F Pediatr 1986;108:9971004 .

22 Koch S, Jäger-Roman E, Lösche G, et al. Antiepileptic drug treatment in pregnant epileptic women: pharmacokinetics and drug side effects in the neonate and neurological outcome at age 6. Acta Paediatr 1996;84:739-46.

23 Di Liberti JH, Farnden PA, Dennis NR, Curry CJR. The fetal valproate syndrome. Am $\mathcal{F}$ Med Genet 1984;19:47381 .

24 Cornblath M, Schwartz R, Aynsley-Green A, Lloyd J. Hypoglycaemia in infancy: the need for a rational definition. Pediatrics 1990;85:834-7.

25 Bien D, Leake R, Haymond M, et al. Measurement of "true" glucose production rates in infancy and childhood with 6,6-dideuteroglucose. Diabetes 1977;26:1016-23.

26 Cowett R, Oh W, Schwartz R. Persistent glucose production during glucose infusion in the neonate. $\mathcal{F}$ Clin Invest 1983;71:467-75.

27 Carter B. Macrosomic Infants of non-diabetic mothers. $\mathcal{F}$ Pediatr 1996;128:439-40.

28 Aynsley-Green A, Polak J, Bloom S, et al. Nesidioblastosis of the pancreas: definition of the syndrome and the managethe pancreas: definition of the syndrome and the management of the severe neonatal hyperinsulinac
caemia. Arch Dis Child 1981;56:496-508.

29 Hawdon J, Aynsley-Green A, Alberti K, Platt M. The role of pancreatic insulin secretion in neonatal glucose regulation. I. Healthy term and preterm infants. Arch Dis Child 1993;68:274-9.

30 Hauser E, Seidl R, Freilinger M, Male C, Herkner K. Hematologic manifestations and impaired liver synthetic function during valproate monotherapy. Brain Dev 1996;18:105-9.

31 Van Wouwe J. Carnitine deficency during valproic acid treatment. Int f Vitam Nutr Res 1995;65:211-14.

32 Bavoux F, Fournier-Perkilou A-I, Wood C, Francoual C, Boccara J-F. Neonatal fibrinogen depletion caused by sodium valproate. Ann Pharmacother 1994;28:1307.

33 Linuma K, Hayasaka K, Narisawa K, et al. Hyperaminoacidaemia and hyperammonaemia in epileptic children treated with valproic acid. Eur f Pediatr 1988;148:267-9.

34 Thurston JH, Carroll JE, Dodson WE, Haubart RE, Tasch V. Chronic valproate administration inhibits ketogenesis in children as well as infant mice. American Neurologist 1982;12:199-200

35 Mortensen P, Gregersen N, Koelvraa S, Christensen E. The occurrence of $\mathrm{C}_{6}-\mathrm{C}_{10}$-dicarboxylic acids in urine from patients and rats treated with dipropylacetate. Biochem Med 1980;24:153-61.

36 Nobukuni Y, Yokoo TT, Ohtani Y, et al. Neonatal onset of medium-chain acyl-CoA dehydrogenase deficiency in two siblings. Brain Dev 1988;10:129-34.

37 Tyni T, Palotie A, Viinikka L, et al. Long-chain 3-hydroxyacyl-coenzyme A dehydrogenase deficency with the G1528C mutation: clinical presentation of thirteen patients. F Pediatr 1997;130:67-76.

38 Rogiers V, Vandenbergh Y, Vercruysse A. Inhibition of gluconeogenesis by sodium valproate and its metabolites in isolated rat hepatocytes. Xenobiotica 1985;15:759-65. 